\title{
UMA PROPOSTA DE FERRAMENTA PARA DIAGNÓSTICO DO NÍVEL DE ENVOLVIMENTO DA GESTÃO DE DESIGN E SUA MATURIDADE.
}

\section{A PROPOSED TOOL FOR DIAGNOSING THE INVOL- VEMENT LEVEL OF DESIGN MANAGEMENT AND ITS MATURITY.}

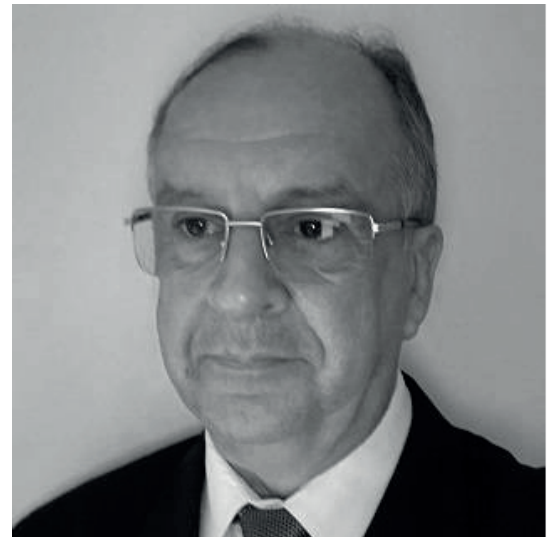

\section{Edson Pacheco Paladini}

Professor pelo Programa de Pós-graduação em

Engenharia de Produção da Universidade Federal de Santa Catarina.

Doutor em Engenharia de Produção - UFSC..

edson.paladini@ufsc.br; paladini@floripa.com.br

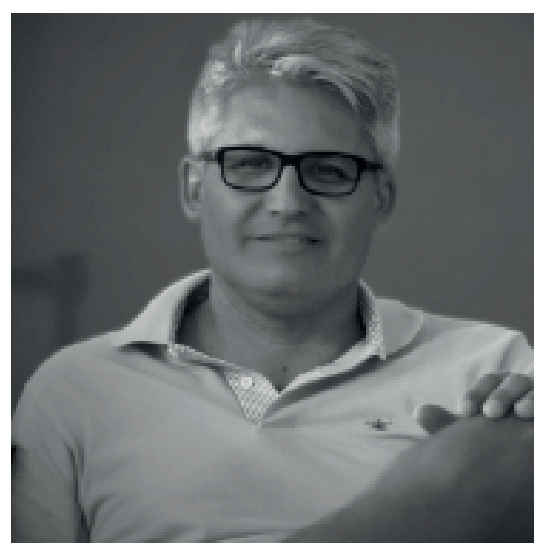

\section{Eugenio Andres Diaz Merino}

Professor da Universidade Federal de Santa Catarina Doutor em Engenharia de Produção pela Universidade Federal de Santa Catarina, UFSC.

eugenio.merino@ufsc.br 


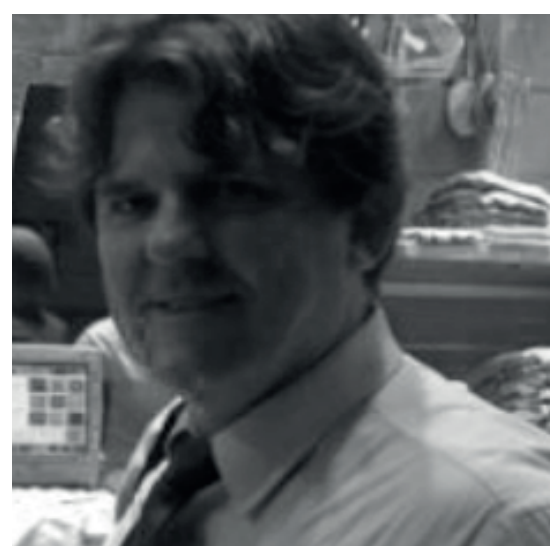

\section{Ricardo Triska}

Professor da Universidade Federal de Santa Catarina Doutor em Engenharia de Produção pela Universidade Federal de Santa Catarina, UFSC.

ricardo.triska@ufsc.br

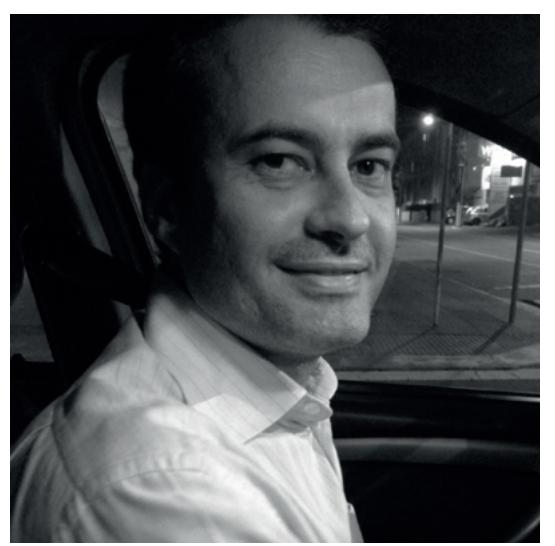

\section{Jorge Elias Dolzan}

Doutorando em Gestão de Design pela Universidade Federal de Santa Catarina - UFSC

Mestre em Ciências da Linguagem pela Universidade do Sul de Santa Catarina - UNISUL jorgedolzan@yahoo.com.br; jorge.dolzan@estacio.br

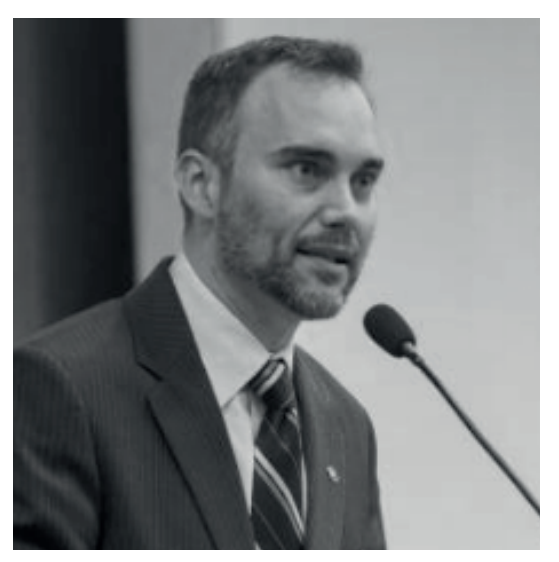

\section{Eduardo Bridi}

Doutorando pelo Programa de Pós Graduação em Engenharia de Produção - UFSC e Departamento de Engenharia - Jönköping University (Suécia).

Mestre em Administração na Universidade Federal de Santa Catarina.

bridi@mrmy.com.br 


\section{RESUMO}

O design pode ser considerado um componente relevante em organizações. Neste contexto, este estudo propõe o desenvolvimento de uma ferramenta para diagnosticar o envolvimento/maturidade da gestão de design nas organizações através de critérios que envolvem níveis da Gestão de Design e seus estágios de desenvolvimento. Iniciado na análise bibliográfica, possibilitou a criação de um instrumento de coleta de dados, seguido de um pré-teste que permitiu a sistematização e análise com finalidade de desenvolver e aplicar o instrumento. Verificou-se que o instrumento solicita ao respondente um nível conceitual alto relativo à gestão de design, além da necessidade de explicar previamente alguns conceitos. Por fim, o formulário ganhou direcionamentos, minimizando julgamentos pessoais, onde as respostas estejam mais baseadas em fatos do que na percepção.

\section{PALAVRAS-CHAVE}

Gestão de Design; Grau de Maturidade; Diagnóstico; Instrumento de Coleta de Dados.

\section{ABSTRACT}

Design can be considered a relevant component in organizations. In this context, this study proposes the development of a tool to diagnose the involvement/maturity of design management in organizations through criteria that involve levels of Design Management and its stages of development. Initiated in the bibliographic analysis, it enabled the creation of a data collection instrument, followed by a pre-test that allowed the systematization and analysis with the purpose of developing and applying the instrument. It was verified that the instrument asks the respondent a high conceptual level regarding the management of design, besides the need to explain some concepts previously. Finally, the form has gained direction, minimizing personal judgments, where the answers are based on facts rather than perception.

\section{KEYWORDS}

Design Management; Degree of Maturity; Diagnosis; Instrument of Data Collection.

\section{INTRODUÇÃO}

Atualmente o design passa a compor a alta esfera corporativa fazendo parte das estratégias de negócios, auxiliando na melhoria da qualidade, que consolidada 
de forma gradual em projetos, programas, políticas, estratégias e na filosofia de design, reconfigura as estruturas corporativas. Compreender se realmente existe o envolvimento do design nos processos organizacionais é requisito fundamental para a gestão do design, cujo entendimento e compreensão se tornam essenciais neste contexto desafiador.

Este estudo parte do pressuposto que um diagnóstico concreto oportunizará uma visão panorâmica da gestão do design em um determinado contexto, o que, de certa forma, demostrará os pontos fortes e fracos a cerca do design e da sua gestão, cujo resultante pode ser um plano de ação ou, em se tratando de um setor da economia, uma política setorial para aumento da performance dos envolvidos. Este trabalho buscou desenvolver uma abordagem relacionando critérios que envolvem a configuração da Gestão de Design definidos pelos autores Martins e Merino (2011) e os estágios da gestão do design definido por Gimeno (2000), tendo como objetivo:

- desenvolver uma ferramenta de diagnóstico da gestão do design a fim de identificar o grau de maturidade desta gestão.

Havendo este enquadramento e parametrização relativos ao grau de maturidade da gestão de design, ter-se-á informações pertinentes para um processo decisório com melhores resultados nos diversos níveis da organização, pois as diretrizes a serem perseguidas e as ações obterão melhor desempenho se adotadas levando em consideração o envolvimento e o grau de maturidade, caso contrário incorre-se no risco de adotar uma estratégia subdimensionada ou superdimensionada para empresa em um momento em que a mesma não está madura ou apta o suficiente para por em prática.

\subsection{METODOLOGIA}

De natureza aplicada e abordagem qualitativa que, segundo Vieira (2008), procura levantar as opiniões e os significados das coisas nas palavras dos participantes na pesquisa, este estudo tem como abordagens a pesquisa exploratória e descritiva cuja finalidade é oferecer um panorama global sobre determinado tema pouco explorado (GIL, 2010). Para isso, adota como procedimentos técnicos a pesquisa bibliográfica e levantamento de dados.

A ferramenta (que pode ser qualificada como um check-list de procedimentos) caracterizou-se como estruturada, com perguntas abertas e fechadas, este último tipo podendo ser de dupla e múltipla escolha. $O$ estudo piloto efetuou uma análise de 4 (quatro) empresas de design de Florianópolis, selecionadas intencionalmente utilizando como parâmetro de pesquisa 3 (três) critérios: 1) de- 
senvolver serviços de design, uma vez que muitas empresas se denominam de design, mais pela força do termo do que pelo serviço que prestam; 2) o número de funcionários (acima de 3), considerando que empresas pequenas não concretizariam muitos dos requisitos, pois grande parte do processo se consolida quando existem equipes; e 3) a existência de sede física, cujo espaço garanta, de alguma forma, a existência de uma estrutura mínima que suporte o trabalho de um grupo. A partir destes parâmetros, buscou-se uma relação de empresas com este perfil, a que mais se mostrou completa foi a lista telefônica online. Esta listagem revelou um total de 7 (sete) empresas de design dentro do perfil estipulado na região geográfica definida - Grande Florianópolis. Em seguida, agendaram-se os horários e os pesquisadores/autores saíram a campo para aplicar a ferramenta, que foi efetuada mediante conversa pessoal. Quatro empresas participaram da aplicação da ferramenta, sendo que 3 (três) delas não tiveram disponibilidade para responder no período de coleta de campo. A definição de empresas de design para a aplicação do estudo piloto foi oportuna, pois os respondentes são profissionais que conhecem o design e ofereceram subsídios importantes para melhorias e ajustes no material final. Por fim, após as aplicações todas as ferramentas foram reunidas e discutidas pelos autores que as analisaram também do ponto de vista da situação, ou seja, do momento de aplicação. O resultado da análise da ferramenta oportunizou a elaboração de uma ferramenta final que culminou na produção deste artigo.

\section{GESTÃO DE DESIGN}

A gestão de design começa a tomar forma nas primeiras décadas do século XX, podendo ser remetida à atuação de Peter Behrens na Empresa AEG - Allgemeine Elektrizitäts Gesellshaft, em Berlim, a partir de 1907 (BÜRDEK, 2006). “Podemos nos reportar ao trabalho de Peter Behrens na AEG no início do século 20 como a primeira contribuição ao design management" (BÜRDEK, 2006, p. 358). Outro ponto marcante aconteceu nos EUA, após a grande crise de 1929. Raymond Loewy, entre outros profissionais, legitimaram o Styling e toda a intervenção do design como ferramenta plástica de venda e de mudança comportamental das empresas, "As habilidades 'específicas' do designer (criatividade, iniciativa, atenção ao detalhe, atenção ao cliente) tornam-se qualidades que um gerente pode utilizar na mudança da empresa" (MARTINS; MERINO, 2011, p. 146).

Nos dois momentos percebe-se que a gestão de design se faz presente quando há a incorporação da inovação, seja ela como elemento tangível dos produtos ou como elemento intangível dos processos. Estes momentos históri- 
cos apresentam mudanças consideráveis nos modelos organizacionais, onde cada vez mais se abandona o método mecanicista e se aproxima de um modelo flexível, "baseado em conceitos como gestão orientada ao cliente, gestão baseada em projetos e gestão da qualidade total, sendo que todas lidam com design" (MOZOTA, 2011, p. 91).

Tal perspectiva está reforçada na afirmação do Design Management Institute (DMI, 2013) em que a gestão de design é conceituada como "a arte e a ciência que possibilita que o design melhore a colaboração e sinergia entre 'design' e 'business' para melhorar a eficácia de projeto". Para Martins e Merino (2011, p. 148), a principal característica que distingue a gestão de design é a "identificação e a comunicação de caminhos pelos quais o design pode contribuir ao valor estratégico da empresa".

Desta forma, a gestão do design pode ser compreendida como a utilização dos recursos de design disponíveis numa organização a fim de contribuir para o alcance das suas metas e seus objetivos. Portanto, a própria organização deve identificar quais são os recursos disponíveis, mas para isso são necessários empreendedores visionários, gestores que sejam responsáveis em acreditar e investir no design da própria empresa e, ao agir desta maneira, reconhecer o design além do desenvolvimento de produtos, afinal o design é fim (bem/serviço), mas, de acordo com Mozota (2011) também é meio (processo). Conforme mencionado por Ritter e Gemuenden (2002) apud Dabrowsk e Savitskaya (2014), estes recursos disponíveis e o background da organização podem estar diretamente ligados à criatividade e ao sucesso do empreendimento. Em suma, a gerência deve ser integradora, necessita reconhecer os artefatos de design e precisa estar capacitada nesta área, promovendo assim a convergência do design e da gestão em seus processos. No que compete a este modelo de gestão que integra o design, os 3 (três) níveis de subdivisão são descritos por Martins e Merino (2011) como: 1) Nível operacional: o nível de projeto; de ordem dos processos e de formação da equipe de design. Iniciado com a demanda por design, que pode originar-se "de uma necessidade de diferenciar um produto, lançar uma marca, desenvolver liderança em design e, finalmente, da carência de implementação de uma nova tecnologia" (MOZOTA, 2011, p. 228). 2) Nível tático: onde se estrutura os procedimentos assegurando viabilidade destes, visando o bom desempenho do design. Dado ao fator prático, neste nível há o aumento da cultura de design na organização, se destacando a função coordenadora; e 3) Nível estratégico: onde o design tem o papel de "unificar e transformar a visão da empresa" (MOZOTA, 2011, p. 227). “Hoje em dia, quando 
um gabinete de design recebe uma encomenda para reformular a imagem de uma empresa, os designers começam por fazer um levantamento dos valores defendidos pela empresa" (DORMER, 1995, p. 177). Aqui se visualiza a estratégia organizacional, define-se a competência central, reunindo informações gerais que possam contribuir para a inovação em processos. É neste que se destaca a função transformadora do design.

A prática da gestão de design necessita permear os 3 (três) níveis, sendo ela uma atividade que deve administrar (planejar, organizar, dirigir e controlar) a função do design, sendo diretamente responsável pelos processos de desenvolvimento de projeto, programas de design; pelas políticas de relacionamento; pelas missões e visões estratégicas; podendo alcançar os valores compondo a filosofia organizacional (GIMENO, 2000). O nível estratégico está diretamente ligado às ações que envolvem as definições de metas e objetivos. O nível tático está no campo do quê se faz, voltando-se a coordenação das atividades. E o nível operacional está no campo do como se faz, do uso dos processos e das ferramentas de desenvolvimento dos projetos (bens/serviços) organizacionais (MARTINS; MERINO, 2011). Neste último as ações "são considerados insuficientes para a inovação, porque há altos níveis de formalização e de controle conflituosas com o caráter dos processos de inovação" (SAUNILA; MÄKIMATTILA; SALMINEN, 2014, p.24). Todavia, para que o processo de inovação ocorra, foi constatado por meio de pesquisa junto a executivos realizada por Rigby e Bilodeau (2011) apud Dabrowsk e Savitskaya (2014) que a cultura é tão importante quanto a estratégia para o sucesso do negócio, seguido pela capacidade de mudança.

De acordo com a proposta de Martins, Merino (2011), deve-se verificar se a configuração da Gestão de Design pode representar a realidade cotidiana de sua aplicação e com que propriedade. Para tanto, considera-se a existência da possibilidade de (1) haver sinergia organizacional entre os setores; se o (2) compartiIhamento das informações gerenciais do design promove melhorias nas decisões de toda a organização; se (3) a organização reconhece o design como estratégia competitiva e inovadora; se (4) as estratégias de design resultam em diferenciais para suportar a estratégia central do negócio; se (5) a gestão pelo design está integrada aos seus processos cotidianos; e se (6) a estratégia de gestão do design pode se tornar a estratégia central da empresa. Relacionando estas 6 (seis) possibilidades com os níveis de gestão do design mais 4 itens criados pelos autores deste artigo, apresenta-se o esquema com 10 (dez) itens que compõem a configuração da gestão do design, este aumento se sustentada no discurso de Alexander Brem, Nico Kreusel e Christian Neusser (2008, p. 424) que tanto as aplicações 
práticas quanto "a pesquisa teórica deve expandir a antiga lista de pré-requisitos e definir uma lista ou matriz de critérios" que se possa usar para estimar o contexto a ser estudado. Por conta disso, e em estreita colaboração com aplicações práticas, a pesquisa teórica deve expandir a antiga lista de pré-requisitos e definir uma lista ou matriz de critérios que as empresas devem usar para estimar a sua própria prontidão para o processo de implementação.

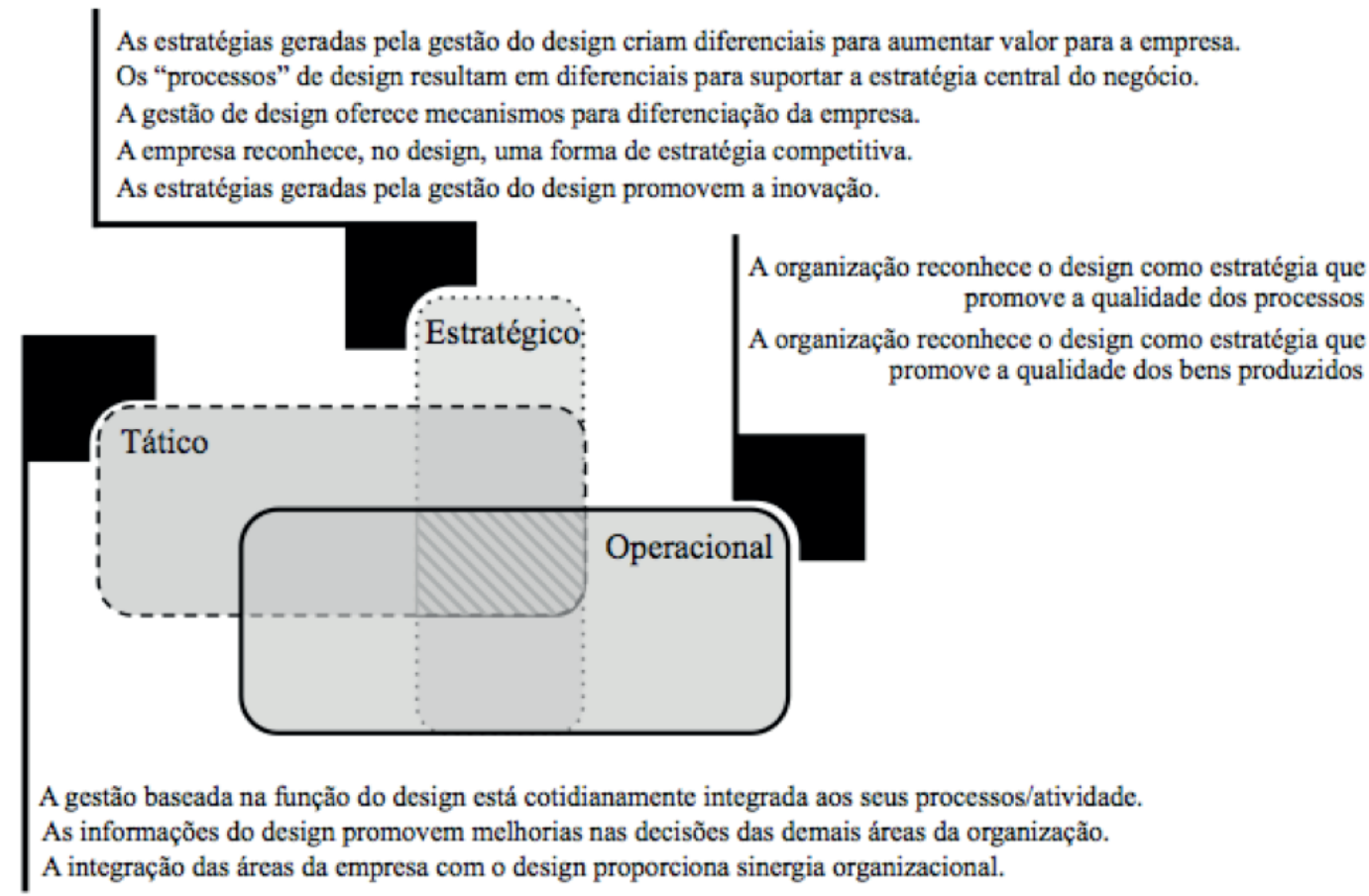

Figura 1: Níveis da gestão de design e fatores de envolvimento.

FONTE: adaptado de MARTINS; MERINO, 2011.

Este arranjo das diretrizes determinantes (envolvimento) da Gestão do Design apresentado na Figura 1 demonstra que esta gestão ocorre nos 3 (três) níveis da empresa, sendo o envolvimento maior na medida em que mais determinantes são encontradas na organização avaliada. Ao se constatar todas as determinantes tem-se um envolvimento máximo, oportunizando constatar o design integrado plenamente aos valores da empresa. A medida que se vai identificando menos determinantes deste arranjo (Figura 3) aproxima-se do design em nível menor de gestão, onde havendo um número reduzido de determinantes fica-se restrito ao desenvolvimento de projetos. Esta escala está intimamente ligada aos cinco estágios de incorporação do design, como aponta Gimeno (2000) e são assim apresentados: 1) Design incorporado filosoficamente, onde o design 
rege e regula toda e qualquer atividade interna ou externa da empresa. 2) Design incorporado estrategicamente, onde a estratégia competitiva da empresa se baseia na aplicação do design em seus três possíveis campos de atuação: produto, comunicação do produto e imagem corporativa. 3) Design incorporado nas políticas organizacionais, resulta em tomadas de decisão estruturadas e a distribuição de recursos para elaborar programas de gestão que permitam o desenvolvimento de diversos programas de design. 4) Design incorporado nos programas da empresa, percebe-se na sistematização estruturada com as fases e os objetivos organizacionais. 5) Design incorporado em projeto, quando a empresa contrata serviços de design terceirizados ou disponibiliza dos serviços de desenvolvimento de produto internamente na empresa. Estes níveis podem ser compreendidos em uma escala (Figura 4), sendo o primeiro nível o mais básico em termos de maturidade (ver item 2.2), incorporando e solidificando a gestão de design à medida que se sobe pelos degraus da figura a seguir:

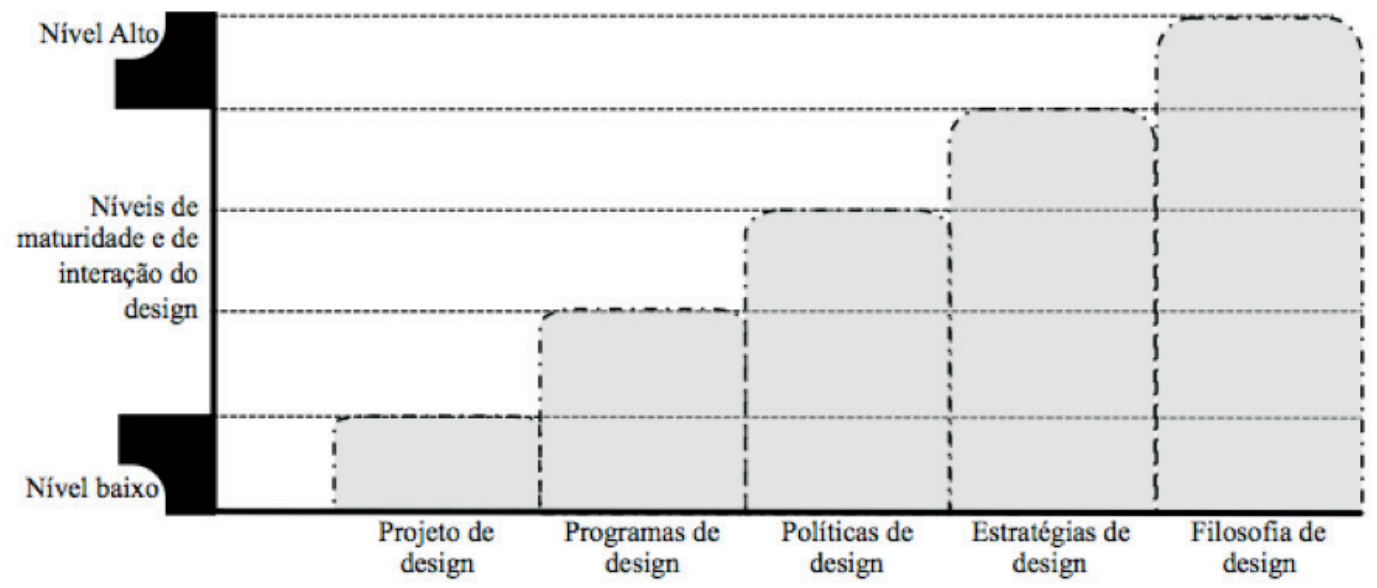

Figura 2: Grau de interação do design numa organização.

FONTE: adaptado de GIMENO, 2000, p. 327.

Tal estrutura ilustra os níveis de excelência do design na empresa na medida em que ela reconhece e incorpora a gestão desta atividade em graus maiores do que em projetos de design. A compreensão do design integrado nestes níveis faz menção a cerca do design apresentados pela Fundación COTEC para la innovación sob a coordenação de Isa Moll e Jordi Montaña (2008), onde o envolvimento de todos é pré-requisito para o alcance da excelência em design; tal envolvimento deve se garantir na integração de todos os trabalhadores da organização; e que exista a garantia de que tal interação seja positiva, 
havendo assim a busca em superar as metas que levam a níveis de qualidade cada vez maiores.

\subsection{O GRAU DE MATURIDADE DA GESTÃO DO DESIGN}

De modo geral, a origem do conceito de maturidade aplicado ao processo de gestão das empresas é atribuída à Crosby (1984), que na década de 1970, desenvolveu um processo para avaliar a institucionalização da gestão da qualidade nas empresas. Desde então, alguns autores vêm refinando o tema. Para Dooley et al. (2001) e para o CMMI (2002), a maturidade é o grau com que um processo ou atividade é institucionalizado e efetivado por toda a organização. Para Rozenfeld et al. (2006), a maturidade de processo é um indicador do quanto a empresa aplica melhores práticas de desenvolvimento de produtos resultando em um melhor desempenho do processo.

O conceito apresentado por Jucá Jr e Amaral (2005), define o nível de maturidade como um indicativo da sofisticação, da estabilidade e frequência com que práticas, técnicas e procedimentos padrão relacionados a uma área especifica são adotados. Assis et al. (2012) conceitua maturidade como a extensão em que o processo é explicitamente definido, gerenciado, medido, controlado e eficaz, afirmando ainda que o Modelo de Maturidade é um referencial usado para avaliar a capacidade dos processos na realização de seus objetivos, localizar oportunidades de melhoria de produtividade e qualidade e de redução de custos, além de planejar e monitorar as ações de melhoria contínua dos processos empresariais.

Ainda não há um consenso a respeito de um modelo oficial para definição do grau de maturidade em determinadas áreas da organização, porém, pode-se fazer uso de alguns modelos já elaborados para necessidades específicas. De acordo com Salviano (2006) apud Cristofari Júnior; De Paula; Fogliatto (2011) os modelos existentes para análise de grau de maturidade oferecem um índice ou valor de referência em maturidade, qual é gerado a partir da análise de dados coletados, mensurando processos e as melhores práticas realizadas na empresa. Na análise do grau de maturidade, as empresas normalmente aplicam um questionário e os resultados obtidos são colocados em uma escala, onde se faz uma análise quantitativa a partir da percepção dos respondentes que estão diretamente envolvidos na execução dos processos (FRASER; MOULTRIE; GREGORY, 2002). Considerando que a maturidade está ligada diretamente com o nível da definição dos processos, mediação, controle, eficiência e eficácia dentro de uma instituição, e que efetivamente seus procedimentos são realizados pela organização, percebe-se que o grau de maturidade é um indicador da maneira 
como as práticas de gestão são efetivadas, visando sempre um desempenho melhor dos processos.

\section{A FERRAMENTA DE DIAGNÓSTICO}

\subsection{ASPECTOS RELEVANTES NA CONSTRUÇÃO DA FERRAMENTA} A resposta para uma pergunta, frequentemente depende de sua formulação. Muitos especialistas acreditam que melhorar a formulação das perguntas pode contribuir muito mais para precisão do que melhorias na amostragem. Tal fato demonstra a importância e preocupação que o pesquisador deve ter na construção do instrumento de pesquisa (Zikmund, 2006). Para McDaniel e Gates (2005), o processo de construção do formulário compreende etapas lógicas e deve ser composto por:

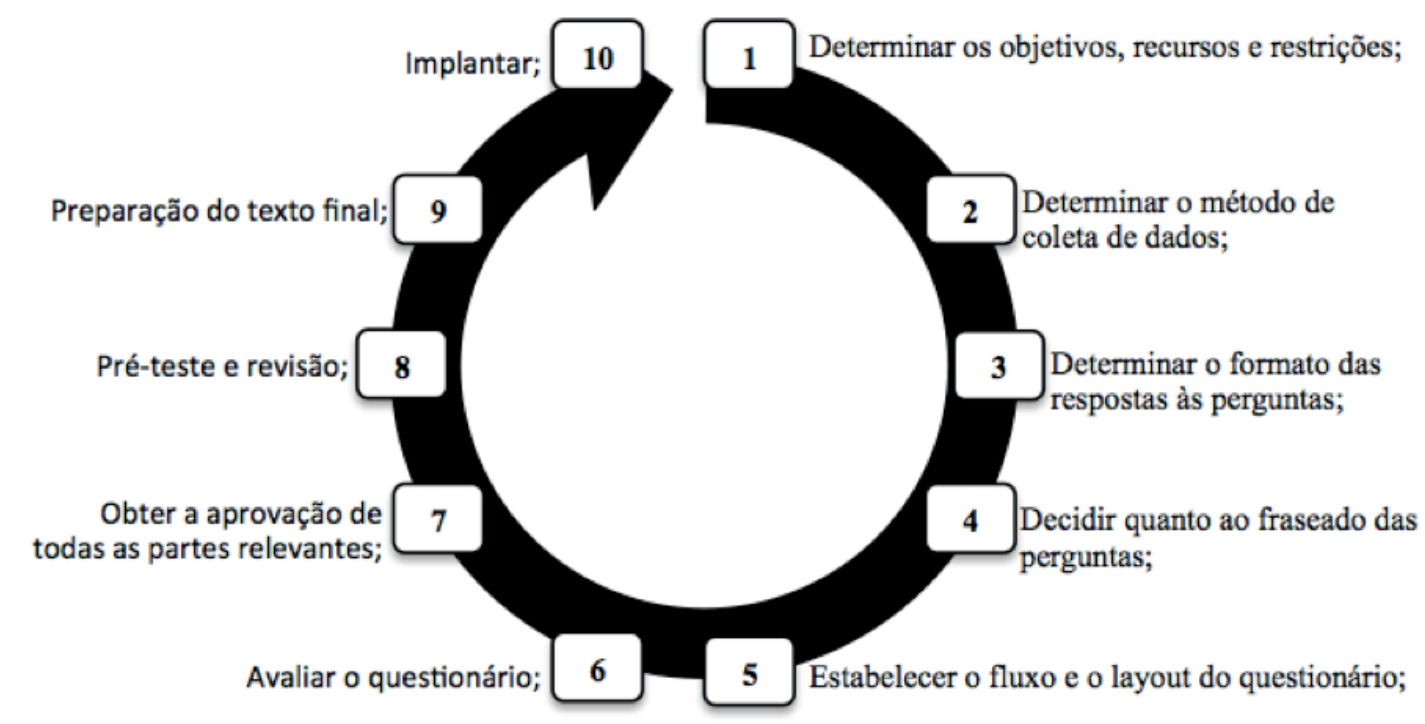

Figura 3: Passos para o processo de formulação do formulário.

FONTE: com base em MCDANIEL e GATES, 2005.

O pré-teste mencionado no item 8 (Figura 3) é um procedimento de verificação que envolve uma execução experimental com um grupo de respondentes para remover problemas fundamentais em um projeto de levantamento (ZIKMUND, 2006, p. 339). São citadas diversas dicas por Malhorta (2012) para se elaborar um formulário, algumas delas são: Verificar se a pergunta é mesmo necessária e se é possível unir perguntas; as perguntas devem ser redigidas superando a incapacidade e a falta de disposição para resposta; deve-se minimizar o esforço do entrevistado; temas delicados no final do questionário; utilizar sempre que possível perguntas estrutu- 
radas; as questões abertas são úteis como perguntas de abertura e para pesquisas exploratórias, devendo ser simples, interessantes e não ameaçadoras; as perguntas gerais devem preceder as de cunho específico; distribuição de forma lógica, ficando para o final as perguntas de classificação e identificação; os questionários devem ser numerados, assim como as questões e as respostas, estas últimas pré-codificadas; linguagem simples e comum atendendo o nível do vocabulário dos entrevistados; evitar perguntas que induzem à resposta determinada; evitar palavras ambíguas (as vezes, ocasionalmente, geralmente, etc.).

\subsection{CONSTRUÇÃO DA FERRAMENTA DE DIAGNÓSTICO:}

Conforme mencionado anteriormente, os seis itens que compões a configuração da gestão de design propostas por Martins e Merino (2011) foram a base para o desenvolvimento da espinha dorsal do formulário composta por 10 (dez) diretrizes apresentadas na Figura 1, e que passaram a ser os objetivos basilares que desenvolveram o instrumento. Estas diretrizes convertidas em questões objetivam, cada qual em sua área, a compreensão do nível envolvimento da organização frente a gestão do design. E a maturidade tomou os graus de interação do Gimeno (2000) - Figura 2. Esta maturidade foi considerada em cada questionamento contribuindo para o desenvolvimento inicial do formulário, como se verifica no quadro a seguir:

\begin{tabular}{|l|l|l|}
\hline $\begin{array}{l}\text { Questões basilares da ferramenta de } \\
\text { diagnóstico do nível de envolvimento } \\
\text { da gestão de design e sua maturidade }\end{array}$ & Envolvimento & Maturidade \\
\hline $\begin{array}{l}\text { A empresa reconhece, no design, uma } \\
\text { forma de estratégia competitiva, um } \\
\text { processo estruturado? }\end{array}$ & ( ) SIM NÃO & $\begin{array}{l}\text { Se sim: A organização reconhece } \\
\text { design como... } \\
\text { ( ) Projeto ( ) Programas ( ) Políti- } \\
\text { cas ( ) Estratégias ( ) Filosofia }\end{array}$ \\
\hline $\begin{array}{l}\text { A gestão baseada na função do design } \\
\text { está cotidianamente integrada aos } \\
\text { seus processos/atividades? }\end{array}$ & ( ) SIM NÃO & $\begin{array}{l}\text { Se sim: A gestão baseada na função } \\
\text { do design é... } \\
\text { ( ) Projeto ( ) Programas ( ) Políti- } \\
\text { cas ( ) Estratégias ( ) Filosofia }\end{array}$ \\
\hline $\begin{array}{l}\text { As estratégias geradas pela gestão do } \\
\text { design criam diferenciais para aumen- } \\
\text { tar valor para empresa? }\end{array}$ & $\begin{array}{l}\text { ( ) SIM ) NÃO } \\
\text { Se sim: As atividades ou estratégias } \\
\text { de design criam diferenciais em... } \\
\text { ( ) Projeto ( ) Programas ( ) Políti- } \\
\text { cas ( ) Estratégias ( ) Filosofia }\end{array}$ \\
\hline
\end{tabular}




\begin{tabular}{|c|c|c|}
\hline $\begin{array}{l}\text { As estratégias geradas pela de gestão } \\
\text { de design criam diferenciais para am- } \\
\text { pliar a inovação? }\end{array}$ & $\begin{array}{l}\text { ( ) SIM } \\
\text { ( ) NÃO }\end{array}$ & $\begin{array}{l}\text { Se sim: As estratégias de gestão de } \\
\text { design tem relação com a inovação } \\
\text { em... } \\
\text { ( ) Projeto ( ) Programas ( ) Políti- } \\
\text { cas ( ) Estratégias ( ) Filosofia }\end{array}$ \\
\hline $\begin{array}{l}\text { A organização reconhece o design } \\
\text { como estratégia que promove a quali- } \\
\text { dade dos bens produzidos? }\end{array}$ & $\begin{array}{l}\text { ( ) SIM } \\
\text { ( ) NÃO }\end{array}$ & $\begin{array}{l}\text { Se sim: As estratégias de gestão de } \\
\text { design tem relação com... } \\
\text { ( ) Projeto ( ) Programas ( ) Políti- } \\
\text { cas ( ) Estratégias ( ) Filosofia }\end{array}$ \\
\hline $\begin{array}{l}\text { A organização reconhece o design } \\
\text { como estratégia que promove a quali- } \\
\text { dade dos processos e serviços? }\end{array}$ & $\begin{array}{l}\text { ( ) SIM } \\
\text { ( ) ) NÃO }\end{array}$ & $\begin{array}{l}\text { Se sim: As estratégias de gestão de } \\
\text { design tem relação com a qualida- } \\
\text { de dos processos e serviços internos } \\
\text { no/nas... } \\
\text { ( ) Projeto ( ) Programas ( ) Políti- } \\
\text { cas ( ) Estratégias ( ) Filosofia }\end{array}$ \\
\hline $\begin{array}{l}\text { A gestão de design oferece mecanis- } \\
\text { mos para diferenciação da empresa? }\end{array}$ & $\begin{array}{l}\text { ( ) SIM } \\
\text { ( ) NÃO }\end{array}$ & $\begin{array}{l}\text { Se sim: A gestão de design cria esta } \\
\text { diferenciação em... } \\
\text { ( ) Projeto ( ) Programas ( ) Políti- } \\
\text { cas ( ) Estratégias ( ) Filosofia }\end{array}$ \\
\hline $\begin{array}{l}\text { As estratégias de design resultam em } \\
\text { diferenciais para suportar a estratégia } \\
\text { central do negócio? }\end{array}$ & $\begin{array}{l}\text { ( ) SIM } \\
\text { ( ) NÃO }\end{array}$ & $\begin{array}{l}\text { Se sim: A gestão de design cria es- } \\
\text { tes diferenciais de suporte da estra- } \\
\text { tégia em... } \\
\text { ( ) Projeto ( ) Programas ( ) Políti- } \\
\text { cas ( ) Estratégias ( ) Filosofia }\end{array}$ \\
\hline $\begin{array}{l}\text { A integração das áreas da empresa } \\
\text { com o Design proporciona sinergia or- } \\
\text { ganizacional? }\end{array}$ & $\begin{array}{l}\text { ( ) SIM } \\
\text { ( ) NÃO }\end{array}$ & $\begin{array}{l}\text { Se sim: Esta sinergia ocorre em... } \\
\text { ( ) Projeto ( ) Programas ( ) Políti- } \\
\text { cas ( ) Estratégias ( ) Filosofia }\end{array}$ \\
\hline $\begin{array}{l}\text { As informações do Design promovem } \\
\text { melhorias nas decisões das demais áre- } \\
\text { as da organização? }\end{array}$ & $\begin{array}{l}\text { ( ) SIM } \\
\text { ( ) ) NÃO }\end{array}$ & $\begin{array}{l}\text { Se sim: As melhorias das decisões } \\
\text { das outras áreas da organização } \\
\text { tem reflexo em... } \\
\text { ( ) Projeto ( ) Programas ( ) Políti- } \\
\text { cas ( ) Estratégias ( ) Filosofia }\end{array}$ \\
\hline
\end{tabular}

Quadro 1: Questionamentos basilares para a ferramenta de diagnóstico (A partir da figura 3). FONTE: Autores 
Além dos questionamentos basilares outras questões como dados de identificação e o tempo de vida da empresa foram introduzidas, pois se mostraram necessárias em um possível cruzamento com o grau de maturidade. Outras questões iniciais sobre conceitos e entendimentos a respeito da gestão de design, que além de preparar o respondente para o tema central possibilita informações coerentes na análise das respostas, também foram idealizadas. Desta forma, no bloco inicial estruturou-se as seguintes questões:

\begin{tabular}{|l|l|}
\hline $\begin{array}{l}\text { Questões iniciais da ferramenta de diagnóstico do nível de envolvi- } \\
\text { mento da gestão de design e sua maturidade }\end{array}$ & \\
\hline Há quanto tempo a empresa está no mercado? & Questão aberta. \\
\hline Quantos funcionários tem atualmente? & Questão aberta. \\
\hline A empresa atua no setor de... & $\begin{array}{l}\text { ( ) Design de produto } \\
\text { ( ) Design gráfico } \\
\text { ( ) Design de moda } \\
\text { ( ) Outros }\end{array}$ \\
\hline Como o(a) Sr.(a) vê o panorama do Design na Grande Florianópolis? & Questão aberta. \\
\hline E seus clientes, praticam a Gestão de Design? & Questão aberta. \\
\hline Seu(s) principal(is) concorrente(s) atua(m) com um design mais ope- & Questão aberta. \\
racional ou mais estratégico? & \\
\hline O que o(a) Sr.(a) entende ser a Gestão de Design? & Questão aberta. \\
\hline
\end{tabular}

Quadro 2: Questionamentos iniciais para a ferramenta de diagnóstico. FONTE: Autores

As questões 1, 2 e 3 eram respectivamente sobre o tempo de atuação da empresa, a quantidade de funcionários e o setor de atuação, elas foram utilizadas como filtro e ofereceram a possibilidade de cruzamento para serem conjecturadas algumas relações conforme serão apresentadas no próximo item. Um questionamento que surgiu durante a aplicação e que aferiu considerações finais pertinentes foi a formação do proprietário da empresa, a princípio a formação parece influenciar na atuação de cada empresa. Sugere-se questionar a formação do entrevistado, pois o cruzamento desta questão poderá oferecer indícios de como a escolaridade/formação técnica pode influenciar a gestão do design. Com estes questionamentos iniciando a ferramenta, seguido pelas questões de envolvimento e maturidade (Quadro 1) fez-se necessário apresentar questionamentos finais, com o objetivo de buscar outras informações importantes. Uma das questões possui o intuito de verificar o enquadramento da empresa de for- 
ma ampla frente ao grau de maturidade em gestão de design. As outras duas possibilitam uma compreensão de como o respondente visualiza a importância da gestão do design em seus negócios. Estas questões se apresentam assim:

\begin{tabular}{|c|c|}
\hline $\begin{array}{l}\text { Questões finais da ferramenta de diagnóstico do } \\
\text { nível de envolvimento da gestão de design e sua } \\
\text { maturidade }\end{array}$ & \\
\hline Em geral, a empresa atua na esfera de: & $\begin{array}{l}\text { ( ) Projeto ( ) Programas ( ) Políticas } \\
\text { ( ) Estratégias ( ) Filosofia }\end{array}$ \\
\hline $\begin{array}{l}\text { O que poderia ser feito para desenvolver a gestão de } \\
\text { design na sua empresa? }\end{array}$ & Questão aberta. \\
\hline $\begin{array}{l}\text { Caso fosse ampliada a gestão de design, o que pode- } \\
\text { ria melhorar em sua empresa? (somente } 1 \text { alternativa } \\
\text { - a principal) }\end{array}$ & $\begin{array}{l}\text { ( ) Entregas no prazo } \\
\text { ( ) Qualidade } \\
\text { ( ) Rentabilidade } \\
\text { ( ) Novos negócios } \\
\text { ( ) Parcerias duradouras } \\
\text { ( ) Melhor imagem da empresa } \\
\text { ( ) Melhoria no atendimento } \\
\text { ( ) Outros: }\end{array}$ \\
\hline
\end{tabular}

Quadro 3: Questionamentos finais para a ferramenta de diagnóstico. FONTE: Autores

\subsection{CRÍTICAS E MELHORIAS NA FERRAMENTA APÓS APLICAÇÃO NA FORMA PILOTO}

Conforme mencionado anteriormente, neste projeto piloto foram coletados dados de quatro empresas, portanto, não se teve pretensão de esgotar o assunto e fazer inferência para o universo, tampouco se tem o intuito de induzir o leitor a fazer este tipo de projeção.

O objetivo é avaliar a ferramenta, tanto sob o aspecto de formatação quanto de captura efetiva das informações necessárias para fazer o diagnostico. Desta forma, a análise abaixo dividiu as questões por blocos, voltados aos objetivos específicos da ferramenta. Para cada bloco seguem as questões e as repostas (em itálico) de cada uma das empresas.

Primeiro objetivo específico da ferramenta: Verificar o entendimento do entrevistado sobre gestão de design. Questões relacionadas: 4, 5, 6, 7, 19, 20 


\begin{tabular}{|l|l|}
\hline QUESTÃO/ENUNCIADO & RESPOSTAS \\
\hline $\begin{array}{l}\text { 4. Como o(a) Sr.(a) vê o panora- } \\
\text { ma de design na Grande Floria- } \\
\text { nópolis? }\end{array}$ & $\begin{array}{l}\text { É bem positivo por conta das empresas de tecnologia e } \\
\text { startups. Público mais maduro. }\end{array}$ \\
\hline & $\begin{array}{l}\text { Não existe! A maioria dos clientes é de fora do município. } \\
\text { arranjar mão de obra qualificada e do cliente compreender } \\
\text { o valor do produto). Tal carência é oportuna, pois abre por- } \\
\text { tas. }\end{array}$ \\
\hline & $\begin{array}{l}\text { Em Florianópolis as oportunidades estão mais no setor de } \\
\text { serviços e tecnologias. Na Grande Florianópolis existem } \\
\text { oportunidades também no setor industrial. }\end{array}$ \\
\hline
\end{tabular}

Quadro 4: Respostas para a Questão 4, coletadas nas entrevistas. FONTE: Autores

O foco da questão 4 era iniciar o assunto ao respondente, a fim de abordar um assunto pertinente ao tema do estudo, e que o mesmo tivesse oportunidade de responder com certo domínio. Percebeu-se que as respostas ficaram divididas, onde os cenários positivo e negativo apareceram havendo de fato um entendimento por parte do pesquisado sobre esta pergunta introdutória, compreendida como um 'quebra-gelo' - forma de ganhar a confiança do entrevistado.

\begin{tabular}{|l|l|}
\cline { 2 - 2 } QUESTÃO/ENUNCIADO & RESPOSTAS \\
\hline $\begin{array}{l}\text { 5. E seus clientes, praticam a a de Design? } \\
\text { Gesto todos. }\end{array}$ & Nem \\
\hline & $\begin{array}{l}\text { Não. } \\
\text { nuitos dos clientes veem o design como diferencial, funcio- } \\
\text { novamente aqui. }\end{array}$ \\
\hline & $\begin{array}{l}\text { Os maiores clientes possuem setores para gerenciar o design, } \\
\text { os pequenos clientes não. }\end{array}$ \\
\hline
\end{tabular}

Quadro 5: Respostas para a Questão 5, coletadas nas entrevistas. FONTE: Autores

Com intuito de começar a abordar a gestão de design, a pergunta 5 sugeriu um enfoque para a clientela da empresa. A estratégia aqui era poder compreender 
como o respondente vê a gestão de design de seu cliente para depois comparar com a visão dele mesmo. As respostas foram todas diferentes, havendo uma reflexão sobre a possibilidade de reformulação da questão de maneira a garantir mais objetividade, oferecendo horizontes de resposta ou espaço para notas, caso o pesquisador deseje um estudo mais quantitativo. Esta transformação pode ser interessante para estudos mais amplos, onde a capacidade do entrevistador não seja plena.

\begin{tabular}{|l|l|}
\hline QUESTÃO/ENUNCIADO & RESPOSTAS \\
\hline $\begin{array}{l}\text { 6. Seu(s) principal(is) concorrente(s) atua }(\mathrm{m}) \text { com } \\
\text { design mais operacional ou mais estratégico? }\end{array}$ & Mais operacional \\
\hline & Mais operacional \\
\hline & Um pouco mais que somente operacional. \\
\hline & De forma estratégica. \\
\hline
\end{tabular}

Quadro 6: Respostas para a Questão 6, coletadas nas entrevistas. FONTE: Autores

No momento da aplicação da questão 6 se percebeu a possibilidade desta ser objetiva com alternativas de respostas fechadas. Esta questão auxilia, assim como as anteriores, a construir didaticamente um caminho do tema abordado, amadurecendo o respondente para as repostas que virão à frente.

\begin{tabular}{|l|l|}
\hline QUESTÃO/ENUNCIADO & RESPOSTAS \\
\hline $\begin{array}{l}\text { 7. O que o(a) Sr.(a) en- } \\
\text { tende ser a Gestão de } \\
\text { Design? }\end{array}$ & Elaboração de todo o desenvolvimento do projeto. \\
\hline & Pensar no design desde o início como parte do processo. \\
\hline & $\begin{array}{l}\text { A preocupação do design como um todo, é "cruzar na área e tam- } \\
\text { bém cabecear"! Desde a prospecção, atendimento, financeiro, pro- } \\
\text { dução... é estar na rua sempre... pensando em projetos para ofere- } \\
\text { cer! }\end{array}$ \\
\hline $\begin{array}{l}\text { Pensar e gerenciar o design em todo o seu percurso desde a ela- } \\
\text { boração das estratégias para a concepção dos produtos, passando } \\
\text { pela gestão do processo até a execução operacional. }\end{array}$ \\
\hline
\end{tabular}

Quadro 7: Respostas para a Questão 7, coletadas nas entrevistas. FONTE: Autores 
Esta é uma questão que se inseriu bem ao propósito do pesquisador de abordar o desenvolvimento da gestão de design. Ela aberta oportunizou respostas que enriquecem o tema questionado contribuindo, para a formação do conceito sobre maneiras de ampliar a gestão de design.

\begin{tabular}{|l|l|}
\hline QUESTÃO/ENUNCIADO & RESPOSTAS \\
\hline $\begin{array}{l}\text { 19. O que poderia ser feito para desenvol- } \\
\text { ver a gestão de design na sua empresa? }\end{array}$ & Preparar e educar o Mercado. \\
\hline & Trabalhar o cliente. \\
\hline & $\begin{array}{l}\text { Ampliar o pensamento do design e desenvolver } \\
\text { e-books e palestras }\end{array}$ \\
\hline & Melhorar a gestão financeira e a gestão do tempo. \\
\hline
\end{tabular}

Quadro 8: Respostas para a Questão 19, coletadas nas entrevistas. FONTE: Autores

Penúltima questão do formulário, a pergunta 19 oportunizou repostas coerentes que, em um estudo amplo, podem fornecer um leque de estratégias interessantes a serem implantadas podendo resultar em um conjunto de respostas capaz de refletir padrões do setor.

\begin{tabular}{|l|l|}
\hline QUESTÃO/ENUNCIADO & RESPOSTAS \\
\hline $\begin{array}{l}\text { 20. Caso fosse ampliada a gestão de design, } \\
\text { o que poderia melhorar em sua empresa? }\end{array}$ & Entregas no prazo. \\
\hline & Rentabilidade. \\
\hline & Novos negócios \\
\hline & Melhor imagem da empresa. \\
\hline
\end{tabular}

Quadro 9: Respostas para a Questão 20, coletadas nas entrevistas. FONTE: Autores

Esta pergunta foi apresentada de maneira objetiva/fechada e o respondente deveria escolher somente uma opção. No momento de resposta nenhum cliente ficou na dúvida entre as opções apontando com convicção diretamente uma reposta, demonstrando um pronto entendimento.

Segundo objetivo específico da ferramenta: Constatar o envolvimento da empresa com a gestão de design. Questões relacionadas: 8, 9, 10, 11, 12, 13, 14, 15, 16, 17 Este bloco de questões relativas ao envolvimento da empresa com a gestão de design possui alternativas de resposta de dupla escolha (sim/não). A necessida- 
de da objetividade com que o respondente deve se posicionar, leva a estratégia de aplicação deste bloco de maneira que as respostas sejam dicotômicas. Por se tratar de um universo específico de empresas de Design, acabou-se coletando 'sim' em todos os quesitos para as 4 empresas, conforme demonstra a tabela 1 em frequência absoluta e relativa.

\begin{tabular}{|c|c|c|c|c|}
\hline QUESTÃO/ENUNCIADO & SIM & NÃO & & \\
\hline & F. Abs. & F. Rel. & F. Abs. & F. Rel. \\
\hline $\begin{array}{l}\text { 8. A empresa reconhece, no design, uma forma de es- } \\
\text { tratégia competitiva, um processo estruturado? }\end{array}$ & 4 & $100 \%$ & 0 & $0 \%$ \\
\hline $\begin{array}{l}\text { 9. A gestão baseada na função do design está cotidia- } \\
\text { namente integrada aos seus processos/atividades? }\end{array}$ & 4 & $100 \%$ & 0 & $0 \%$ \\
\hline $\begin{array}{l}\text { 10. As estratégias geradas pela gestão do design criam } \\
\text { diferenciais para aumentar valor para empresa? }\end{array}$ & 4 & $100 \%$ & 0 & $0 \%$ \\
\hline $\begin{array}{l}\text { 11. As estratégias geradas pela de gestão de design } \\
\text { criam diferenciais para ampliar a inovação? }\end{array}$ & 4 & $100 \%$ & 0 & $0 \%$ \\
\hline $\begin{array}{l}\text { 12. A organização reconhece o design como estratégia } \\
\text { que promove a qualidade dos bens produzidos?* }\end{array}$ & 4 & $100 \%$ & 0 & $0 \%$ \\
\hline $\begin{array}{l}\text { 13. A organização reconhece o design como estratégia } \\
\text { que promove a qualidade dos processos e serviços?* }\end{array}$ & 4 & $100 \%$ & 0 & $0 \%$ \\
\hline $\begin{array}{l}\text { 14. A gestão de design oferece mecanismos para dife- } \\
\text { renciação da empresa? }\end{array}$ & 4 & $100 \%$ & 0 & $0 \%$ \\
\hline $\begin{array}{l}\text { 15. As estratégias de design resultam em diferenciais } \\
\text { para suportar a estratégia central do negócio? }\end{array}$ & 4 & $100 \%$ & 0 & $0 \%$ \\
\hline $\begin{array}{l}\text { 16. A integração das áreas da empresa com o Design } \\
\text { proporciona sinergia organizacional? }\end{array}$ & 4 & $100 \%$ & 0 & $0 \%$ \\
\hline $\begin{array}{l}\text { 17. As informações do Design promovem melhorias } \\
\text { nas decisões das demais áreas da organização? }\end{array}$ & 4 & $100 \%$ & 0 & $0 \%$ \\
\hline Total & 40 & $100 \%$ & 0 & $0 \%$ \\
\hline
\end{tabular}

Quadro 10: Questões relativas ao envolvimento com a Gestão de Design FONTE: Seminário EPS510027D/EPS410028M UFSC 2014/1 - Autores

O que se percebeu no momento da aplicação foi a necessidade de explicar muitas das perguntas ao respondente. Outro ponto relevante neste momento foi de que ao responder uma pergunta o entrevistado tratava de outras questões deixando, em alguns casos, o questionário repetitivo. 
Terceiro objetivo específico da ferramenta: Identificar grau de maturidade da gestão de design. Questões relacionadas: 8.1, 9.1, 10.1, 11.1, 12.1, 13.1, 14.1, 15.1, 16.1, 17.1, 18.

Este conjunto de questões de múltipla escolha oferece elementos para classificar a maturidade das empresas no que diz respeito à gestão do design. Com exceção da questão 18, as demais só eram perguntadas caso houvesse algum tipo de envolvimento (questões do segundo objetivo específico) da empresa com a gestão de design. Então, a empresa poderia ser classificada conforme os graus de interação de Gimeno (2000), Figura 2 (projeto de design, programa de design, política de design, estratégia de design e filosofia de design). Os resultados levantados foram:

\begin{tabular}{|l|l|l|l|l|l|}
\hline QUESTÃO/ENUNCIADO & $\begin{array}{l}\text { Projeto } \\
\text { de design }\end{array}$ & $\begin{array}{l}\text { Programas } \\
\text { de design }\end{array}$ & $\begin{array}{l}\text { Políticas } \\
\text { em design }\end{array}$ & $\begin{array}{l}\text { Estraté- } \\
\text { gias de } \\
\text { design }\end{array}$ & $\begin{array}{l}\text { Filoso- } \\
\text { fia de } \\
\text { design }\end{array}$ \\
\hline $\begin{array}{l}8.1 \text { Se sim: A organização reco- } \\
\text { nhece design como... }\end{array}$ & $25 \%$ & -- & $25 \%$ & $25 \%$ & $25 \%$ \\
\hline $\begin{array}{l}\text { 9.1 Se sim: A gestão baseada na } \\
\text { função do design é caracterizada } \\
\text { como... }\end{array}$ & $25 \%$ & -- & -- & $50 \%$ & $25 \%$ \\
\hline $\begin{array}{l}10.1 \text { Se sim: As atividades ou es- } \\
\text { tratégias de design criam dife- } \\
\text { renciais em... }\end{array}$ & -- & -- & $25 \%$ & $50 \%$ & $25 \%$ \\
\hline $\begin{array}{l}11.1 \text { Se sim: As estratégias de } \\
\text { gestão de design tem relação } \\
\text { com a inovação em... }\end{array}$ & -- & $25 \%$ & $25 \%$ & $25 \%$ & $25 \%$ \\
\hline $\begin{array}{l}12.1 \text { Se sim: As estratégias de } \\
\text { gestão de design tem relação } \\
\text { com a qualidade final dos bens } \\
\text { em... }\end{array}$ & - & -- & $25 \%$ & $50 \%$ & $25 \%$ \\
\hline $\begin{array}{l}13.1 \text { Se sim: As estratégias de } \\
\text { gestão de design tem relação } \\
\text { com a qualidade dos processos e } \\
\text { serviços internos no/nas... }\end{array}$ & -- & $50 \%$ & $25 \%$ & $25 \%$ & -- \\
\hline $\begin{array}{l}14.1 \text { Se sim: A gestão de design } \\
\text { cria esta diferenciação em... }\end{array}$ & -- & -- & -- & $50 \%$ & $50 \%$ \\
\hline
\end{tabular}




\begin{tabular}{|l|l|l|l|l|l|}
\hline $\begin{array}{l}\text { 15.1 Se sim: A gestão de design } \\
\text { cria estes diferenciais de suporte } \\
\text { da estratégia em... }\end{array}$ & -- & -- & $25 \%$ & $50 \%$ & $25 \%$ \\
\hline $\begin{array}{l}16.1 \text { Se sim: Esta sinergia ocorre } \\
\text { em... }\end{array}$ & $25 \%$ & -- & -- & $25 \%$ & $50 \%$ \\
\hline $\begin{array}{l}17.1 \text { Se sim: As melhorias das de- } \\
\text { cisões das outras áreas da orga- } \\
\text { nização tem reflexo em... }\end{array}$ & -- & $25 \%$ & -- & $75 \%$ & - \\
\hline Total & $7,5 \%$ & $10 \%$ & $15 \%$ & $42,5 \%$ & $25 \%$ \\
\hline
\end{tabular}

Quadro 11: Questões relativas ao grau de maturidade da Gestão de Design. FONTE: Seminário EPS510027D/EPS410028M UFSC 2014/1 - autores.

Neste conjunto de questões percebeu-se interpretações diferentes do próprio entrevistador tanto de alguns termos da pergunta quanto das repostas ouvidas. Para minimizar foi entregue aos respondentes, definições de cada estagio a ser assinalado - será que vale a pena inserir aqui aquela figura.

Em algumas questões percebeu-se que o respondente refletia uma postura, mas na hora de optar por uma alternativa escolhia um estágio que não era condizente com seu discurso. Caso, por exemplo, da questão 15 (As estratégias de design resultam em diferenciais para suportar a estratégia central do negócio?), onde um dos respondentes deixou claro não valorizar e não ter plano de negócios, nem missão e visão de sua empresa, mas definiu seu estágio como "Estratégia de design". Desta forma, percebe-se a necessidade de buscar maior coerência por meio de subitens que possam dar mais fidedignidade ao dado coletado.

\begin{tabular}{|l|l|}
\hline QUESTÃO/ENUNCIADO & RESPOSTAS \\
\hline 18. Em geral, a empresa atua na esfera de: & ( ) Projeto de design; \\
\hline & ( ) Programas de design; \\
\hline & ( ) Políticas em design; \\
\hline & ( ) Estratégias de design; \\
\hline & ( ) Filosofia de design; \\
\hline
\end{tabular}

Quadro 12: Questão relativa ao enquadramento visto pela empresa.

FONTE: Seminário EPS510027D/EPS410028M UFSC 2014/1 - autores. 
Na questão 18, onde foi verificado o enquadramento geral da empresa no grau de maturidade, contatou-se que uma está na esfera de Projeto de Design, uma em Programa de Design e outras duas empresas na esfera de Política de Design. Esta questão tinha a pretensão de constatar o estagio global que a empresa se reconhecia frente ao design, mas se avalia como desnecessária, pois as 10 questões anteriores trouxeram de forma mais detalhada esta informação.

\section{CONSIDERAÇÕES FINAIS}

Este trabalho possibilitou, a partir do estudo bibliográfico e, posteriormente, da aplicação, coleta e análise dos dados, desenvolver e criticar a ferramenta chegando a considerações sobre o instrumento de coleta a ponto de oportunizar ajustes que visam melhorar a ferramenta.

De maneira objetiva, as principais considerações sobre a ferramenta foram: 1) Ampliar a atenção ao perfil do entrevistado (formação e nível de conhecimento a cerca do design). 2) Transformar questões abertas em fechadas. 3) Alterar a linguagem das questões facilitando o entendimento. 4) Formular opções de respostas que facilitem o enquadramento, algo semelhante a um check list de estratégias e ações efetivadas pela empresa. 5) Oferecer opções de resposta que reduzam erros não amostrais relacionados ao ego dos respondentes, pois podem tender ao enquadramento de níveis de maturidade maiores do que efetivamente se encontram. 6) As opções de respostas relativas ao nível de maturidade devem ser revistas, pois não captam a maturidade efetiva. 7) As opções relativas ao envolvimento cumprem o seu papel e ainda ofereceram a oportunidade de se propor uma escala de enquadramento do envolvimento com a Gestão do Design. Sugere-se a seguinte classificação:

\begin{tabular}{|l|l|}
\hline Quantitativo de respostas afirmativas & $\begin{array}{l}\text { Escala de envolvimento da Gestão } \\
\text { de Design }\end{array}$ \\
\hline Não apresenta resposta afirmativa & Não há Gestão de Design \\
\hline Apresenta entre 1 e 3 respostas afirmativas & Gestão de Design incipiente \\
\hline Apresenta entre 4 e 6 respostas afirmativas & Gestão de Design moderada \\
\hline Apresenta entre 7 e 9 respostas afirmativas & Gestão de Design avançada \\
\hline Apresenta 10 respostas afirmativas & Gestão de Design plena \\
\hline
\end{tabular}

Quadro 13: Escala de enquadramento do envolvimento com a Gestão do Design FONTE: Autores. 
Com a consideração das críticas propostas, em uma eventual pesquisa com amostragem maior, o instrumento de coleta poderia ser adaptado para o autopreenchimento do respondente.

Por fim a ferramenta oferece uma compreensão do envolvimento da empresa coma Gestão do Design, porém não permite definir o grau de maturidade, pois tomando os graus de interação de Gimeno (2000) literalmente gera-se um formulário complexo e de difícil entendimento, mesmo por parte de especialista da área, o que pode refletir em erros não amostrais.

Pode-se considerar que houve limitações de ordem temporal e de acesso às demais unidades amostrais do universo definido apesar de não haver o intuito de coletar dados para avaliar a gestão das empresas, mas sim de efetuar um pré-teste do instrumento de coleta para o desenvolvimento da ferramenta. Como sugestão para trabalhos futuro direciona-se ações que deem continuidade ao trabalho atual, implantando os direcionamentos de melhoria e os seus respectivos indicadores de desempenho.

\section{REFERÊNCIAS BIBLIOGRÁFICAS}

ASSIS, B. F. S P.; MACHADO, L. G.; ANJOS, M. C. Metodologia para análise de maturidade de inovações sustentáveis. Revista eletrônica Sistemas \& Gestão. v. 7, 2012, p. 416-427.

BREM, A.; KREUSEL, N.; NEUSSER, C. Perfomance measurement in SMEs: literature review and results from a German case study. Globalisation and Small Business, Vol. 2, No. 4, 2008, p. 411-427. Disponível em: https://www.academia. edu/164244/ acesso em: 23/abr./2015.

BÜRDEK, B. E. Design: história, teoria e prática do design de produtos. São Paulo: Blücher, 2006.

CMMI - CAPABILITY MATURITY MODEL INTEGRATION. Version 1.1. Pittsburgh: Carnegie Mellon Institute, mar. 2002. Disponível em:<http://www.sei.cmu.edu/ reports/02tr029.pdf>. Acesso em: 15 set. 2009.

CRISTOFARI JÚNIOR, C. A.; DE PAULA, I. C.; FOGLIATTO, F. S. Método de análise de maturidade e priorização de melhorias na gestão do Processo de Desenvolvimento de Produtos. Produção, v. 20, no.3 São Paulo, 2010.

CROSBY, B. P. Qualidade é investimento: a arte de garantir a qualidade. Rio de Janeiro: José Olympo, 1984.

DMI - DESIGN MANAGEMENT INSTITUTE - DMI. What is design management? Disponível em: http://www.dmi.org/dmi/html/aboutdmi/design_management. htm Acessado em: 20 ago. 2013. Tradução livre do autor. 
DOOLEY, K.; SUBRA, A.; ANDERSON, J. Maturity and its impact on the new product development project performance. Research in Engineering Design, v. 13, 2001, p. 23-29.

DORMER, Peter. Os significados do design moderno: A caminho do século XXI. Porto: Centro Português de Design, 1995.

DABROWSKA, J.; SAVITSKAYA, I. When culture matters: exploring the open innovation paradigm. Business Innovation and Research, Vol. 8, No. 1, 2014, p 94 118. Disponível em <http://www.inderscience.com/storage/f845111036191227. pdf $>$ acessado em: 24/04/2015.

FORCELLINI, F. A.; ROZENFELD, H. Gestão de desenvolvimento de produtos: uma referência para a melhoria do processo. São Paulo: Saraiva, 2006.

FRASER, P.; MOULTRIE, J.; GREGORY, M. The use of maturity models / grids as a tool in assessing product development capability. IEEE Institute of Electrical and Electronics Engineers, 2002. Disponível em: http://ieeexplore.ieee.org/stamp/stamp. jsp?tp=\&arnumber=1038431\&isnumber=22257. Acesso em: 15 set. 2009.

GIL, A. C. Métodos e técnicas de pesquisa social. São Paulo: Atlas, 2010.

GIMENO, J. M. I. La gestión del diseño en la empresa. Madrid: McGraw-Hill, 2000. JUCÁ Jr., A. S.; AMARAL, D. C. Estudos de caso de maturidade em gestão de projetos em empresas de base tecnológica. In: ENCONTRO NACIONAL DE ENGENHARIA DE PRODUÇÃO, 2005. Anais. Porto Alegre - RS: ABEPRO, 2005.

MALHORTA, N. Pesquisa de marketing: uma orientação aplicada. 6 ed. Porto Alegre: Bookman, 2012.

MARTINS, R. F. de F; MERINO, E. A. D. A gestão de design como estratégia organizacional. Londrina: Eduel; Rio de Janeiro: Rio Books, 2011.

MCDANIEL, C.; GATES, R. Fundamento de pesquisa de marketing. 4 ed. São Paulo: LTC., 2005.

MOLL, I.; MONTAÑA, J. (Coord.). Diseño e innovación. La gestión del diseño em la empresa. Fundación COTEC para la innovación. Madrid: Gráficas Arias Montano, S. A., 2008.

MOZOTA, B. B. de. Gestão do design: usando o design para construir valor de marca e inovação corporativa. Porto Alegre: Bookman, 2011.

SAULINA, M.; MÄKIMATTILA, M. SALMINEN, J. Matrix structure for supporting organisational innovation capability. Business Innovation and Research, Vol. 8, No. 1, 2014, p. 20-35. Disponível em: http://www.inderscience.com/storage/ f114310186579212.pdf acesso em: 24/abr./2015.

VIEIRA, S. Como escrever uma tese. 6. ed. São Paulo: Atlas, 2008.

ZIKMUND, Willian G. Princípios de pesquisa de marketing. 2 ed. São Paulo:Thomson, 2006. 
Eduardo Bridi é Empresário, Administrador, Mestre em Administração e Doutorando pela Universidade Federal de Santa Catarina sendo realizado parte na Jönköping University (Suécia).

Coordenador Geral do Evento Internacional Conexão Suécia 2016.

Vogal da Junta Comercial do Estado de Santa Catarina.

Trabalha há 18 anos gerenciando pesquisa de marketing, de satisfação, de análise sensorial e de cliente oculto em multinacionais, avaliando serviços e atendimento. Conferencista na Equipotel e Conotel, maior feira e congresso de hotelaria da América Latina.

Professor de graduação e pós-graduação em disciplinas de Administração, Marketing e Pesquisa Mercadológica.

Desenvolveu Prêmio Mérito em Administração utilizado pelo Conselho Regional de Administração de Santa Catarina.

Autor do livro Gestão e Avaliação da Qualidade em Serviços para Organizações Competitivas: estratégias básicas e o cliente misterioso. Editora Atlas.

Jorge Elias Dolzan é Professor do Centro Universitário Estácio de Santa Catarina. Atuou como Diretor de Ensino do Município de São José (2013) e Pró-reitor de Pós-Graduação na Estácio de Santa Catarina (2013-2014). Atual coordenador da CPA da Estácio Santa Catarina. Tem experiência na área de Desenho Industrial, com ênfase em Programação Visual e Projeto de Produto, atuando principalmente nos seguintes temas: design, criatividade, moda, gestão de design e metodologia.

Edson Pacheco Paladini é Professor Titular do Departamento de Engenharia de Produção e Sistemas da Universidade Federal de Santa Catarina.

Membro Titular da Academia Brasileira da Qualidade. Doutorado em Engenharia de Produção (UFSC, 1992), Mestrado em Engenharia de Sistemas (UFPb - Campina Grande - 1979), Especialização em Administração da Produção (UFPb, 1981) e Graduação em Matemática (UFSC, 1975).

Atua nas áreas de Engenharia, Gestão e Avaliação da Qualidade.

É autor de diversos livros sobre temas inseridos em suas áreas de atuação e de artigos técnicos publicados em periódicos qualificados no país e no exterior.

Integrou o Comitê de Avaliação dos Programas de Pós-graduação da CAPES na área das Engenharias III.

Coordenador do Programa de Pós-graduação em Engenharia de Produção da UFSC (2002-2006).

Autor dos textos: Gestão Estratégica da Qualidade (duas edições); Gestão da Qualidade: 
Teoria e Prática (sete edições); Avaliação Estratégica da Qualidade (duas edições); Qualidade Total na Prática (duas edições), entre outros.

Eugenio Andres Diaz Merino é Professor associado IV da Universidade Federal de Santa Catarina e coordena o Núcleo de Gestão de Design e o Laboratório de Design e Usabilidade. Tem experiência na área de Design, com ênfase em Gestão de Design, Design Universal, Design Inclusivo e Design Saúde, e na área de engenharia, especificamente com ergonomia, produto e processo. Participa dos programas de pós-graduação em Design e Engenharia de Produção ambos da UFSC. Faz parte do grupo de avaliadores do INEP/MEC e do Conselho Estadual de Educação de Santa Catarina na avaliação de cursos. Realizou Estagio Sênior na Universidad Politécnica de Valencia (Espanha - CAPES). É pesquisador CNPq (PQ1C), Coordenador do Comité Assessor do CNPq (CA DI) e líder do grupo de pesquisa em Gestão de Design. Membro do Grupo Assessor Especial da Diretoria de Relações Internacionais da CAPES (GAE-DRI).

Ricardo Triska é Professor associado 2 da Universidade Federal de Santa Catarina, lotado no Departamento de Expressão Gráfica, compõe o quadro de Docentes Permanentes do Programa de Pós-graduação em Design, níveis mestrado e doutorado, e do curso de Bacharelado em Design. Desenvolveu projetos na área de Ciência da Informação, com ênfase no processo de Transferência da Informação, atuando nas áreas de planejamento de produtos, serviços e sistemas de informação; automação de bibliotecas e bibliotecas digitais. Também desenvolveu projetos nas áreas de gestão do conhecimento e aprendizagem organizacional. Seus projetos atuais se concentram em Linguagem Subliminar, Processos Corporativos, Design de Interface e no Design da Informação. Coordenador da Área de Arquitetura, Urbanismo e Design junto à CAPES(2011-2014). Reconduzido para o período 2014-2017. Conselheiro Titular do Conselho Técnico Científico de Ensino Superior / CAPES (2014-2017).

Recebido em: 31/01/2017

Aceito em: 29/03/2017 